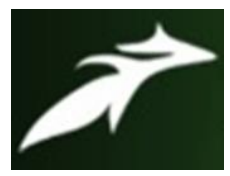

Javed Akhtar Ansari et al, International Journal of Advances in Agricultural Science and Technology,

Vol.8 Issue.9, September-2021, pg. 70-82

ISSN: 2348-1358

Impact Factor: 6.057

NAAS Rating: 3.77

\title{
KNOWLEDGE AND ADOPTION BEHAVIOUR OF FARMERS TOWARDS IMPROVED TOMATO PRODUCTION PRACTICES IN SONBHADRA DISTRICT OF UTTAR PRADESH
}

\author{
Javed Akhtar Ansari ${ }^{1}$; Dipak Kumar Bose ${ }^{2}$; Jahanara ${ }^{3}$ \\ ${ }^{1}$ M.Sc. Ag. (Agricultural Extension and Communication), SHUATS (Prayagraj) \\ ${ }^{2}$ Associate Professor, Department of Agriculture Extension and Communication, SHUATS (Prayagraj) \\ ${ }^{3}$ Head, Department of Agriculture Extension and Communication, SHUATS (Prayagraj) \\ Author's e-mail: jansari766@gmail.com \\ DOI: 10.47856/ijaast.2021.v08i9.009
}

\begin{abstract}
India being a sub-tropical country, ideal for fruit and vegetable production and stands as second largest producer of vegetable. Tomato is the most cultivating vegetable crop in Uttar Pradesh but to ensure food security and to impart the new technology to farmers, the knowledge, attitude and adoption level of farmers should be studied. Thus, the present study was formulated in Sonbhadra district of Uttar Pradesh. Four villages were selected from Ghorwal taluk, 30 respondents from 4 villages constitutes the respondents. Primary data collected from the respondents were analysed with appropriate statistical tools. It can be inferred that majority of the respondents were middle aged, illiterate, had agriculture as their main occupation, possess below 1 hectare of land holding, had 3-10 years of experience in tomato cultivation and farming with medium level of mass media exposure, risk taking ability and progressiveness; earns medium level of annual income. Meanwhile, most of them had medium level of knowledge, attitude and adoption. Whereas, socio-economic characteristics like age, education, mass media exposure, annual income, farming experience and progressiveness had positive and significant association with the knowledge and attitude level of respondents.
\end{abstract}

Keywords: Knowledge, Adoption, Attitude, Tomato, Sonbhadra

\section{Introduction}

Agriculture is the backbone of our country. It has got a prime role in Indian economy. Agriculture is not only responsible for food supply to 1.3 billion population, but also contribute around 16.5 per cent of country's GDP with tremendous domestic and export marketing potential. India is second largest producer of vegetable in the world (surpass only by China) 


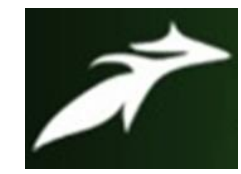

Javed Akhtar Ansari et al, International Journal of Advances in Agricultural Science and Technology, Vol.8 Issue.9, September-2021, pg. 70-82

ISSN: 2348-1358

Impact Factor: 6.057

NAAS Rating: 3.77

accounting for about 12 per cent of the world production. Indian farmers grow an amazing number of different vegetable, but tomato, onion, cabbage, potato and cauliflower accounts for 60 per cent of the total production. Presently, India is the largest producer of okra in the world and stands second in the production of onion, brinjal, tomato, potato, cabbage and cauliflower. Potato is the dominating vegetable grown in India marked by the production of 51.31 million tonnes followed by onion with the production of 23.26 million tonnes and brinjal with the production of 12.8 million tonnes (Anonymous 2018a).

In India, Uttar Pradesh is the leading producer of vegetables (283.16 million tonnes) amongst all the states, followed by West Bengal (276.95 million tonnes). However, with reference to productivity, Tamil Nadu is the leading state with the productivity of 27.5 tonn per ha followed by Kerala (22 t ha) and Chandigarh (18 t hac). In India total area under vegetable crops of 7.981 Million ha and production of 21577 million tonnes. In India Tomato crop is grown in about 599 thousand hectares area with a total production and productivity of about 11149.0 thousand metric tones and 60.9 metric tones per hectares. respectively (Horticulture statistics division, 2020).

Anang et al. (2013) reported that the most pressing constraints identified were inadequate finance (lack of capital), high cost of inputs and low price of the produce. These setbacks have served as disincentives to tomato production in the area. Aggrey et al. (2016) reported $98 \%$ of farmers mentioned 'pests and diseases' as their biggest constraint in tomato production. Other constraints included intensive labour, and costs of pesticides among others. The most commonly mentioned method of dealing with pests and diseases was through spraying with synthetic pesticides. Hadole et al. (2017) showed that majority (65.71\%) of the farmers were having medium level of knowledge about package of practices for tomato cultivation, while 18.57 and 15.71 per cent farmers fell in high and low knowledge level category, respectively. Kumar et al. (2018) reported that 68 percent respondents comes under 


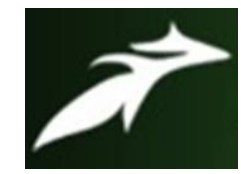

Javed Akhtar Ansari et al, International Journal of Advances in Agricultural Science and Technology, Vol.8 Issue.9, September-2021, pg. 70-82

ISSN: 2348-1358

Impact Factor: 6.057

NAAS Rating: 3.77

medium and 19 percent respondent comes under high adoption categories and remaining 13 percent respondent's adoption level is low about scientific tomato cultivation practices respectively.

Tomato carves for itself a distinct niche in the realm of the vegetable crops. Owing to its acclimatization to a wide variety of environment with their characteristic climatic and cultural conditions, as well as its high nutritive value. tomato remains in the focus of the horticulture industry, as is evidenced by an increase in its cultivation ever since the mid nineteenth century. In present era of global and liberal agriculture farmers are eager to earn more money from per unit. So it becomes important to assess the adoption behaviour of farmers for modern post harvest practices is necessary since these are complementary and supplementary in augmentation of production along with quality of produce to fetch higher prices.

Since there is wide gap between agricultural technologies produced in research institutions and adoption of such technologies by small scale farmers and rural households. Meena et al (2009) noticed that technical intervention through training programmes increase the 5 knowledge level of small-scale farmers in food processing and preservation aspects. Nain et al (2013) suggested dissemination of information regarding income and employment opportunities in horticulture and related issues at a pre-college age through the use of the high school agriculture classroom whereas Chahal et al (2014) advocated participatory methods like learning by doing farm practices in conditions closely resembling their farming situations for transfer of horticultural technologies.

Uttar Pradesh is the fourth largest state of India. The total area under vegetable crops is about 1256 ha and production 27.70 million tones. The area under Tomato crop in Uttar Pradesh is about 12.8 thousand hectares with production of 8.8 lakh tones and productivity of 16.4 tonnes/ha (Horticulture statistics division, 2020). Sonbhadra district of Uttar Pradesh is the important tomato growing district due to favourable climatic condition and availability of proper 


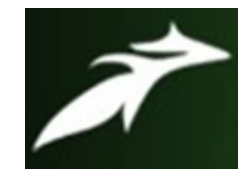

Javed Akhtar Ansari et al, International Journal of Advances in Agricultural Science and Technology, Vol.8 Issue.9, September-2021, pg. 70-82

ISSN: 2348-1358

Impact Factor: 6.057

NAAS Rating: 3.77

marketing facilities etc. The increase in area under tomato crop in Sonbhadra has brought change in social as well as economic conditions of the farmers.

Increasing agricultural productivity is critical for ensuring global food security, but this may not be sufficient. To sustainably achieve the goals of food security, food availability needs to be also increased through reductions in the post-harvest process at farm, retail and consumer levels. Considering the post-harvest losses, huge quantity of vegetable production is reduced from the food chain. Therefore it becomes inevitable to identify the operations and channels where losses are considerable and to understand the adoption behaviour of farmers to towards post-harvest management practices.

Not only improvement in technology in future for these operations and channels is important but also proper dissemination of the technology and farmer's understanding about the same is equally important which will lead towards more availability of produce. The farmer can save his valuable produce and get more prices in the market. The reduction in losses in different channels and adoption of post-harvest management practices will help in providing the quality produce for the consumers and hence all stakeholders including farmers, marketing persons and consumers will be benefited. Keeping in view the existing post-harvest losses the present study has been planned to understand the adoption behaviour of tomato growers for production practices.

\section{Statement of problem}

Tomato is the major vegetable cultivation crops which can be supplement the food need of country in a substantial way as it has achieved tremendous popularity over the last century. Tomato production in India has made tremendous progress with the development of new technologies. Due to complexity in different technology sometimes farmers find it difficult to understand and they lag behind in the adoption of recommended package of practices. In this 


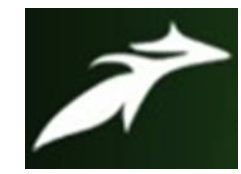

Javed Akhtar Ansari et al, International Journal of Advances in Agricultural Science and Technology,

Vol.8 Issue.9, September-2021, pg. 70-82

ISSN: 2348-1358

Impact Factor: 6.057

NAAS Rating: 3.77

context, the need was felt to study the extent of adoption of tomato cultivation practices. In this context, the following objectives of the study were formulated;

1. To ascertain the socio- economic profile of the respondents.

2. To determine the knowledge of the respondents towards improved tomato production practices.

3. To determine the attitude of the respondents towards improved tomato production practices.

4. To access the adoption of improved tomato production practices.

5. To find out the association between socio economic profile with knowledge and attitude of respondents.

\section{Methodology}

For the study, the research design adopted was descriptive in nature since the phenomenon was already occurred. Sonbhadra district of Uttar Pradesh is selected purposively for the study because maximum farmers produce tomato crop. There are 8 blocks in Sonbhadra district of Uttar Pradesh, out of which Ghorawal block has been selected purposively because maximum area comes under tomato crop. There are 339 villages in Ghorawal Block out of which four villages were selected namely, Adhoura, Basi, Chari and Duba were selected purposely based on the maximum area covered under Tomato. From each village, 30 respondents were selected for the study. Thus, from four village; 120 respondents were selected which constitutes the primary respondents of the study. Primary data collected from the respondents were tabulated, analysed and presented as follows. 


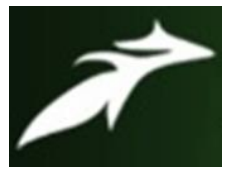

Javed Akhtar Ansari et al, International Journal of Advances in Agricultural Science and Technology, Vol.8 Issue.9, September-2021, pg. 70-82

ISSN: 2348-1358

Impact Factor: 6.057

NAAS Rating: 3.77

\section{Results and Discussion}

The socio-economic profile of the respondents were studied under various characteristics and the results were presented under table.1.

Table.1. Socio-economic profile of the respondents $(n=120)$

\begin{tabular}{|c|c|c|c|c|}
\hline S. No. & Characteristics & Category & Frequency & Percentage \\
\hline \multirow[t]{3}{*}{1} & \multirow[t]{3}{*}{ Age (in years) } & Young $(<30)$ & 24 & 20.00 \\
\hline & & Middle(30-50) & 65 & 54.17 \\
\hline & & Old $(>50)$ & 31 & 25.83 \\
\hline \multirow[t]{6}{*}{2} & \multirow[t]{6}{*}{ Education } & Illiterate & 29 & 24.17 \\
\hline & & Primary & 18 & 15.00 \\
\hline & & Upper primary & 16 & 13.33 \\
\hline & & Secondary & 21 & 17.50 \\
\hline & & Higher secondary & 24 & 20.00 \\
\hline & & Graduate and above & 12 & 10.00 \\
\hline \multirow[t]{3}{*}{3} & \multirow[t]{3}{*}{ Annual Income } & Low & 29 & 24.17 \\
\hline & & Medium & 57 & 47.50 \\
\hline & & High & 34 & 28.33 \\
\hline \multirow[t]{4}{*}{4} & \multirow[t]{4}{*}{ Occupation } & Agriculture & 73 & 60.83 \\
\hline & & Agriculture + Labour & 15 & 12.50 \\
\hline & & Agriculture + Business & 9 & 7.50 \\
\hline & & Agriculture + Service & 23 & 19.17 \\
\hline
\end{tabular}




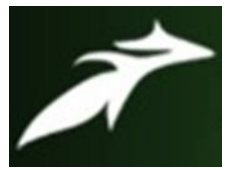

Javed Akhtar Ansari et al, International Journal of Advances in Agricultural Science and Technology, Vol.8 Issue.9, September-2021, pg. 70-82

ISSN: 2348-1358

Impact Factor: 6.057

NAAS Rating: 3.77

\begin{tabular}{|c|c|c|c|c|}
\hline \multirow[t]{4}{*}{5} & \multirow[t]{4}{*}{ Land holding } & Below 1 hectare & 56 & 46.67 \\
\hline & & 1-2 hectare & 24 & 20.00 \\
\hline & & 2-3 hectare & 19 & 15.83 \\
\hline & & Above 3 hectare & 21 & 17.50 \\
\hline \multirow[t]{3}{*}{6} & \multirow{3}{*}{$\begin{array}{c}\text { Experience in } \\
\text { tomato cultivation }\end{array}$} & Less than 3 years & 19 & 15.83 \\
\hline & & $3-10$ years & 64 & 53.33 \\
\hline & & More than 10 years & 37 & 30.83 \\
\hline \multirow[t]{3}{*}{7} & \multirow{3}{*}{$\begin{array}{c}\text { Mass media } \\
\text { exposure }\end{array}$} & Low & 21 & 17.50 \\
\hline & & Medium & 62 & 51.67 \\
\hline & & High & 37 & 30.83 \\
\hline \multirow[t]{3}{*}{8} & \multirow{3}{*}{$\begin{array}{c}\text { Farming } \\
\text { experience }\end{array}$} & Less than 3 years & 23 & 19.17 \\
\hline & & $3-10$ years & 59 & 49.17 \\
\hline & & More than 10 years & 38 & 31.66 \\
\hline \multirow[t]{3}{*}{9} & \multirow{3}{*}{$\begin{array}{c}\text { Risk bearing } \\
\text { capacity }\end{array}$} & Low & 37 & 30.83 \\
\hline & & Medium & 48 & 40.00 \\
\hline & & High & 35 & 29.17 \\
\hline \multirow[t]{3}{*}{10} & \multirow[t]{3}{*}{ Progressiveness } & Low & 29 & 24.17 \\
\hline & & Medium & 74 & 61.67 \\
\hline & & High & 17 & 14.16 \\
\hline
\end{tabular}

From table.1, it can be concluded that more than half of the respondents were middle aged (54.17\%), followed by old aged (25.83\%) and remaining 20 per cent were young. Majority of the 


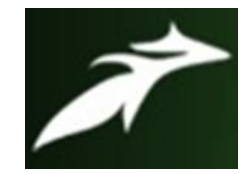

Javed Akhtar Ansari et al, International Journal of Advances in Agricultural Science and Technology, Vol.8 Issue.9, September-2021, pg. 70-82

ISSN: $2348-1358$

Impact Factor: 6.057

NAAS Rating: 3.77

respondents were illiterate $(24.17 \%)$, followed by higher secondary $(20 \%)$, secondary $(17.50 \%)$, primary (15\%), upper primary (13.33\%) and graduate and above (10\%). Higher percentage of the respondents had agriculture as their main occupation (60.83\%), followed by 19.17 per cent of respondents had agriculture + service, 12.50 per cent of respondents had agriculture + labour and 7.50 per cent of respondents had agriculture + business as their major occupation. Nearly half of the respondents had below 1 hectare of land holding (46.67\%), followed by 20 per cent of respondents had 1-2 hectare of land holding, 17.50 per cent of respondents had land holding above 3 hectare and only 15.83 per cent of respondents had 2-3 hectares of land holding.

More than half of the respondents had 3-10 years of experience in tomato cultivation (53.33\%), followed by 30.83 per cent and 15.83 per cent of respondents had more than 10 years and less than 3 years of experience in tomato cultivation respectively. Nearly more than half of the respondents had medium level of mass media exposure $(51.67 \%)$, followed by high $(30.83 \%)$ and low (17.50\%) level of mass media exposure. Nearly half of the respondents had medium level of annual income (47.50\%), followed by 28.33 per cent and 24.17 per cent of respondents earns high and low level of annual income. Higher percentage of the respondents had 3-10 years of experience (49.17\%), followed by more than 10 years of experience $(31.66 \%$ ) and less than 3 years of farming experience (19.17\%). Most of the respondents had medium level of risk bearing capacity (40\%), followed by low (30.83\%) and high level $(29.17 \%)$ of risk bearing capacity. Nearly two-third of the respondents had medium level of progressiveness (61.67\%), followed by low (24.17\%) and high (14.16\%) level of progressiveness.

Knowledge level of respondents towards improved tomato production practices was studied and presented in table. 2 and fig. 2 . 


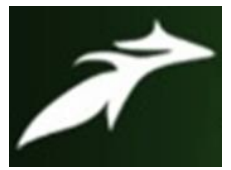

Javed Akhtar Ansari et al, International Journal of Advances in Agricultural Science and Technology, Vol.8 Issue.9, September-2021, pg. 70-82

ISSN: 2348-1358

Impact Factor: 6.057

NAAS Rating: 3.77

Table.2. Distribution of respondents based on their knowledge level

$(\mathbf{n}=\mathbf{1 2 0})$

\begin{tabular}{|c|c|c|c|}
\hline \multirow{2}{*}{ S. No. } & Category & \multicolumn{2}{|c|}{ Response } \\
\cline { 3 - 4 } & & $f$ & $\%$ \\
\hline 1 & Low & 31 & 25.83 \\
\hline 2 & Medium & 61 & 50.83 \\
\hline 3 & High & 28 & 23.33 \\
\hline
\end{tabular}

From table.2, it can be seen that half of the respondents $(50.83 \%)$ had medium level of knowledge, followed by low (25.83\%) and high (23.33\%) level of knowledge towards improved tomato production practices.

Attitude level of respondents towards improved tomato production practices was studied and presented in table.3.

Table.3. Distribution of respondents based on their attitude level

$(\mathbf{n}=\mathbf{1 2 0})$

\begin{tabular}{|c|c|c|c|}
\hline S. No. & Category & \multicolumn{2}{|c|}{ Response } \\
\cline { 3 - 4 } & & $f$ & $\%$ \\
\hline 1 & Low & 24 & 20.00 \\
\hline 2 & Medium & 62 & 51.67 \\
\hline 3 & High & 34 & 28.33 \\
\hline
\end{tabular}

From table.3, it can be understood that nearly more than half of the respondents had medium level of attitude towards improved tomato production practices (51.67\%), followed by high (28.33\%) and low (20\%) level of attitude towards improved tomato production practices. 


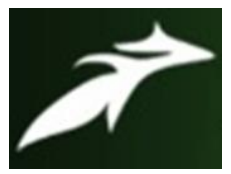

Javed Akhtar Ansari et al, International Journal of Advances in Agricultural Science and Technology, Vol.8 Issue.9, September-2021, pg. 70-82

ISSN: 2348-1358

Impact Factor: 6.057

NAAS Rating: 3.77

Adoption level of respondents towards improved tomato production practices was studied and presented in table.4.

Table.4. Distribution of respondents based on their adoption level

$(\mathbf{n}=120)$

\begin{tabular}{|c|c|c|c|}
\hline \multirow{2}{*}{ S. No. } & Category & \multicolumn{2}{|c|}{ Response } \\
\cline { 3 - 4 } & & $f$ & $\%$ \\
\hline 1 & Low & 27 & 22.50 \\
\hline 2 & Medium & 64 & 53.33 \\
\hline 3 & High & 29 & 24.17 \\
\hline
\end{tabular}

From table.4, it can be seen that higher percentage of the respondents had medium level of adoption (53.33\%) towards improved tomato production practices, followed by 24.17 per cent and 22.50 per cent of respondents had high and low level of adoption towards improved tomato production practices.

The association between socio-economic profile with knowledge and attitude level of respondents towards improved tomato production practices was studied and presented in table.5.

Table.5. Association between socio-economic profile with knowledge and attitude of respondents

\begin{tabular}{|c|l|c|c|c|c|}
\hline S. No. & \multicolumn{1}{|c|}{ Variables } & ${ }^{\prime} r$ ' value & Regression & $\begin{array}{c}\text { Standard } \\
\text { error } \\
\text { Co - efficient }\end{array}$ & ${ }^{\prime} \mathbf{t}^{\text {' value }}$ \\
\hline $\mathrm{X}_{1}$ & Age & $0.277^{* *}$ & -.101 & 1.023 & -.099 \\
\hline $\mathrm{X}_{2}$ & Educational status & $0.525^{* *}$ & $1.932^{* *}$ & .464 & $4.167^{* *}$ \\
\hline
\end{tabular}




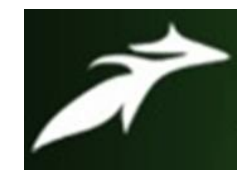

Javed Akhtar Ansari et al, International Journal of Advances in Agricultural Science and Technology, Vol.8 Issue.9, September-2021, pg. 70-82

ISSN: 2348-1358 Impact Factor: 6.057 NAAS Rating: 3.77

\begin{tabular}{|c|l|c|c|c|c|}
\hline $\mathrm{X}_{3}$ & Occupation & 0.127 & .077 & .343 & .224 \\
\hline $\mathrm{X}_{4}$ & Land holding & -.049 & -.588 & 1.841 & -.319 \\
\hline $\mathrm{X}_{5}$ & Experience in tomato & -0.072 & .403 & 1.863 & .216 \\
\hline $\mathrm{X}_{6}$ & Mass media exposure & $0.260^{* *}$ & .065 & .063 & 1.034 \\
\hline $\mathrm{X}_{7}$ & Annual income & $0.284^{* *}$ & .342 & .853 & .401 \\
\hline $\mathrm{X}_{8}$ & Farming experience & $0.256^{* *}$ & -.665 & .999 & -.666 \\
\hline $\mathrm{X}_{9}$ & Risk bearing capacity & 0.031 & 0.087 & 0.136 & 0.641 \\
\hline $\mathrm{X}_{10}$ & Progressiveness & $0.101^{* *}$ & $2.519 *$ & 1.374 & $0.073 *$ \\
\hline
\end{tabular}

$\mathbf{R}^{2}=\mathbf{0 . 5 3}$

$\mathbf{F}=\mathbf{2 . 7 4 3}$

$\mathbf{a}=\mathbf{1 5 1 . 6 7 7}$

NS = Not Significant $*$ = Significant at 5\%, $* *=$ Significant at $10 \%$.

From table.5, it can be seen that socio-economic characteristics like age, education, mass media exposure, annual income, farming experience and progressiveness had positive and significant association with the knowledge and attitude level of respondents at 10 per cent level of significance. Whereas, occupation, risk bearing capacity had non-significant association with the knowledge and attitude level of respondents. Land holding and experience in tomato cultivation had negative and non-significant association with the knowledge and attitude level of the respondents. 


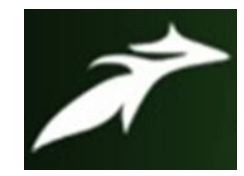

Javed Akhtar Ansari et al, International Journal of Advances in Agricultural Science and Technology, Vol.8 Issue.9, September-2021, pg. 70-82

ISSN: 2348-1358

Impact Factor: 6.057

NAAS Rating: 3.77

\section{Conclusion}

From the study, it can be concluded that majority of the respondents were middle aged, illiterate, had agriculture as their main occupation, possess below 1 hectare of land holding, had 3-10 years of experience in tomato cultivation and farming with medium level of mass media exposure, risk taking ability and progressiveness; earns medium level of annual income. Meanwhile, most of them had medium level of knowledge, medium level of attitude and medium level of adoption. Whereas, socio-economic characteristics like age, education, mass media exposure, annual income, farming experience and progressiveness had positive and significant association with the knowledge and attitude level of respondents at 10 per cent level of significance. There are number of technical, social and economic factors constraint of postharvest management practices of tomato cultivation. Major technical constraints included medium awareness and adoption of tomato growers. Hence, it is suggested that special farmer training programmes should be implemented at filed levels and farmers should be made more conscious about the advantages of post-harvest management practices of tomato cultivation.

\section{REFERENCES}

[1]. Anonymous (2018a) Horticultural Statistics at a glance. pp 1-482. Ministry of agriculture and farmers welfare, Department of Agriculture.

[2]. Aggrey Ocan David, Atuhaire and jors Erik (2016) Knowledge, Attitudes, and Practices of Tomato Producers and Vendors in Uganda, Uganda National Association of Community and Occupational Health, Kampala, Uganda.

[3]. Anang Tetteh Benjamin, Zulkarnain Ahmed Zakaria and Yusif Suleiman (2013) Production Constraints and Measures to Enhance the Competitiveness of the Tomato Industry in Wenchi Municipal District of Ghana, American Journal of Experimental Agriculture 3(4): 824-838, 2013

[4]. Chahal VP, Nain MS, Rashmi S and Chandel SS (2014) A study on cognitive and psychomotor factors of hill farmers on adoption of agri-horti farming system. J Agri Sci 84:1550-54.

[5]. Hadole S.M., Parmeshwari B. Pawar and Ugale (2017) Relationship between selected characteristics of tomato growers and their adoption level of recommended technology in Nashik district of Maharashtra, State Agriculture Update Volume 12 |210-214

[6]. Meena M S, Kumar A, Singh K M and Meena H R (2009) Farmers" Attitude Towards PostHarvest Issues of Horticultural Crops. Indian Res J Ext Edu 9:15-19. 


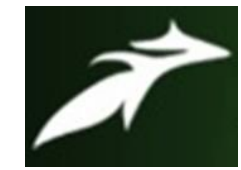

Javed Akhtar Ansari et al, International Journal of Advances in Agricultural Science and Technology, Vol.8 Issue.9, September-2021, pg. 70-82

ISSN: 2348-1358

Impact Factor: 6.057

NAAS Rating: 3.77

[7]. Nain M S, Singh R, Sangeetha V, Chandel S S, Kumar P and Peer J A (2013) Strategies for entrepreneurship development through fruit production in Jammu and Kashmir state. Indian Agr Res Inst 33:165-71

[8]. Horticultural Statistics Division, 2020.

https://agricoop.nic.in/sites/default/files/Horticulture\%20Statistics\%20at\%20a\%20Glance-2020.pdf 